University of New Hampshire

University of New Hampshire Scholars' Repository

Physics Scholarship

Physics

$12-10-2008$

\title{
Formation of even-numbered hydrogen cluster cations in ultracold helium droplets
}

S. Jaksch

A. Mauracher

A. Bacher

S. Denifl

F. Ferreira de Silva

See next page for additional authors

Follow this and additional works at: https://scholars.unh.edu/physics_facpub

Part of the Physics Commons

\section{Recommended Citation}

The following article appeared in J. Chem. Phys. 129, 224306 (2008); doi: 10.1063/1.3035833 and may be found at http://dx.doi.org/10.1063/1.3035833.

This Article is brought to you for free and open access by the Physics at University of New Hampshire Scholars' Repository. It has been accepted for inclusion in Physics Scholarship by an authorized administrator of University of New Hampshire Scholars' Repository. For more information, please contact Scholarly.Communication@unh.edu. 


\section{Authors}

S. Jaksch, A. Mauracher, A. Bacher, S. Denifl, F. Ferreira de Silva, H. Schoebel, Olof E. Echt, T. D. Maerk, M. Probst, D. K. Bohme, and P. Scheier 


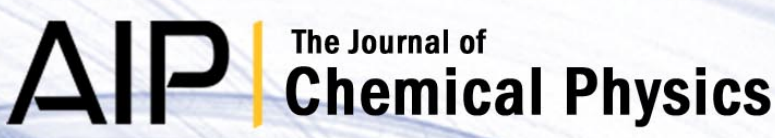

Formation of even-numbered hydrogen cluster cations in ultracold helium droplets

S. Jaksch, A. Mauracher, A. Bacher, S. Denifl, F. Ferreira da Silva et al.

Citation: J. Chem. Phys. 129, 224306 (2008); doi: 10.1063/1.3035833

View online: http://dx.doi.org/10.1063/1.3035833

View Table of Contents: http://jcp.aip.org/resource/1/JCPSA6/v129/i22

Published by the American Institute of Physics.

\section{Additional information on J. Chem. Phys.}

Journal Homepage: http://jcp.aip.org/

Journal Information: http://jcp.aip.org/about/about_the_journal

Top downloads: http://jcp.aip.org/features/most_downloaded

Information for Authors: http://jcp.aip.org/authors

\section{ADVERTISEMENT}
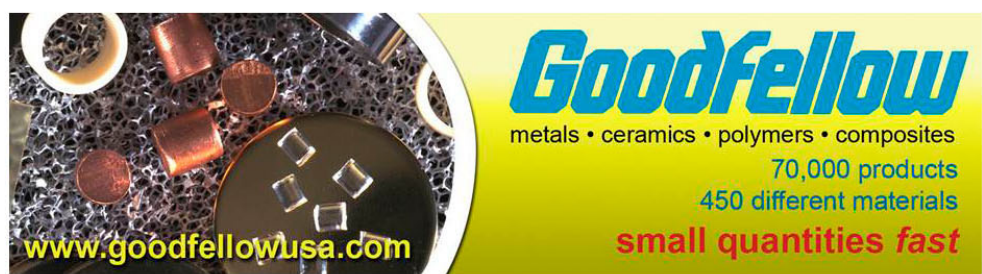


\title{
Formation of even-numbered hydrogen cluster cations in ultracold helium droplets
}

\author{
S. Jaksch, ${ }^{1}$ A. Mauracher, ${ }^{1}$ A. Bacher, ${ }^{1}$ S. Denifl, ${ }_{4}^{1}$ F. Ferreira da Silva, ${ }^{1}$ H. Schöbel, ${ }^{1}$ \\ O. Echt, ${ }^{2}$ T. D. Märk, ${ }^{1,3}$ M. Probst, ${ }^{1}$ D. K. Bohme, ${ }^{4}$ and P. Scheier ${ }^{1, a)}$ \\ ${ }_{1}^{1}$ Institut für Ionenphysik und Angewandte Physik, Leopold Franzens Universität, Technikerstr. 25, \\ A-6020 Innsbruck, Austria \\ ${ }^{2}$ Department of Physics, University of New Hampshire, Durham, New Hampshire 03824, USA \\ ${ }^{3}$ Department of Plasma Physics, Comenius University, SK-84248 Bratislava, Slovakia \\ ${ }^{4}$ Department of Chemistry, York University, Toronto, Ontario M3J 1P3, Canada
}

(Received 22 October 2008; accepted 5 November 2008; published online 10 December 2008)

\begin{abstract}
Neutral hydrogen clusters are grown in ultracold helium nanodroplets by successive pickup of hydrogen molecules. Even-numbered hydrogen cluster cations are observed upon electron-impact ionization with and without attached helium atoms and in addition to the familiar odd-numbered $\mathrm{H}_{n}{ }^{+}$. The helium matrix affects the fragmentation dynamics that usually lead to the formation of overwhelmingly odd-numbered $\mathrm{H}_{n}^{+}$. The use of high-resolution mass spectrometry allows the unambiguous identification of even-numbered $\mathrm{H}_{n}{ }^{+}$up to $n \cong 120$ by their mass excess that distinguishes them from $\mathrm{He}_{n}{ }^{+}$, mixed $\mathrm{He}_{m} \mathrm{H}_{n}{ }^{+}$, and background ions. The large range in size of these hydrogen cluster ions is unprecedented, as is the accuracy of their definition. Apart from the previously observed magic number $n=6$, pronounced drops in the abundance of even-numbered cluster ions are seen at $n=30$ and 114 , which suggest icosahedral shell closures at $\mathrm{H}_{6}{ }^{+}\left(\mathrm{H}_{2}\right)_{12}$ and $\mathrm{H}_{6}{ }^{+}\left(\mathrm{H}_{2}\right)_{54}$. Possible isomers of $\mathrm{H}_{6}{ }^{+}$are identified at the quadratic configuration interaction with inclusion of single and double excitations (QCISD)/aug-cc-pVTZ level of theory () 2008 American Institute of Physics. [DOI: 10.1063/1.3035833]
\end{abstract}

\section{INTRODUCTION}

Hydrogen clusters have attracted interest from diverse communities. One of the earliest goals has been the production of intense beams of hydrogen clusters at high kinetic energies in order to fuel thermonuclear devices. ${ }^{1,2}$ As of today, cluster beams have been successfully injected into the HL-1M tokamak and HT-7 superconducting tokamak. ${ }^{3,4}$ Another interesting development has been the observation that nuclear fusion can be initiated by heating deuterium clusters with femtosecond lasers; this technique ultimately may lead to the development of tabletop neutron sources. ${ }^{5}$

$\mathrm{H}_{3}{ }^{+}$ions play an important role in the chemistry of interstellar clouds as efficient protonators of neutral molecules, and they may act as traps for noble gas atoms in astrophysical objects. ${ }^{6,7} \mathrm{H}_{2} \mathrm{D}^{+}$, rapidly formed from $\mathrm{H}_{3}{ }^{+}$by exothermic proton-deuteron exchange, efficiently deuterates other molecules. ${ }^{8}$

The quantum nature of hydrogen clusters has been another area of interest. ${ }^{9,10}$ Path-integral calculations suggest that small parahydrogen clusters are superfluid ${ }^{11,12}$ although the possible quenching of superfluidity in clusters containing a "magic number" of molecules is a controversial issue. ${ }^{13,14}$ Experiments demonstrate that hydrogen clusters embedded in helium droplets remain fluxional at temperatures well below the bulk triple point of hydrogen ${ }^{15-18}$ but direct experimental evidence for superfluidity is still lacking. ${ }^{19}$ The tran-

\footnotetext{
a) Author to whom correspondence should be addressed. Electronic mail: paul.scheier@uibk.ac.at.
}

sition of confined molecular hydrogen clusters to a metallic state has been subject of recent theoretical studies. ${ }^{20}$

When free hydrogen clusters are ionized by electrons or photons, one observes predominantly odd-numbered cluster ions $\mathrm{H}_{n}{ }^{+21-28}$ The low intensity of even-numbered $\mathrm{H}_{n}{ }^{+}$arises from the large exothermicity of the reaction

$$
\mathrm{H}_{2}^{+}+\mathrm{H}_{2} \rightarrow \mathrm{H}_{3}{ }^{+}+\mathrm{H},
$$

for which an exothermicity of $1.727 \mathrm{eV}$ can be computed from the $\mathrm{H}_{2}{ }^{+}$bond strength ${ }^{29}$ and $\mathrm{H}_{2}$ proton affinity. ${ }^{30}$ The hydrogen dimer $\left(\mathrm{H}_{2}\right)_{2}$ is very weakly bound, therefore a similarly large reaction energy is released after vertical ionization of $\left(\mathrm{H}_{2}\right)_{2} \cdot{ }^{31}$ According to an ab initio direct dynamics calculation, vertical ionization of the $\mathrm{H}_{2}$ dimer, trimer, or hexamer leads to rapid ejection of an energetic hydrogen atom and a vibrationally hot $\mathrm{H}_{3}{ }^{+32}$. This reaction will be quickly followed by emission of one or more $\mathrm{H}_{2}$. Indeed, electron-impact ionization of neutral $\left(\mathrm{H}_{2}\right)_{m}$ clusters that were size-selected by a diffraction grating results in $\mathrm{H}_{3}{ }^{+}$as the most abundant fragment ion for parent sizes up to $m=17 .{ }^{33}$

The prevalence of odd-numbered $\mathrm{H}_{n}{ }^{+}$in experiments has stimulated various theoretical studies of their ground state geometric structures, isomeric structures, dissociation energies, the occurrence of particularly stable sizes (magic numbers), ${ }^{34-44}$ vibrational frequencies, ${ }^{35,40,43,45-47}$ and finitetemperature properties. ${ }^{48}$ Very much less is known about even-numbered $\mathrm{H}_{n}{ }^{+}$. Their production up to $\mathrm{H}_{14}{ }^{+}$upon ionization of preformed neutral hydrogen clusters has been reported $^{21,23,49}$ but the low abundance and limited experimental mass resolution make it difficult to rule out possible 
contributions from background ions, or cluster ions containing deuterium. ${ }^{50}$ In 1979 Mathur and Hasted ${ }^{51}$ reported the observation of $\mathrm{H}_{10}{ }^{+}, \mathrm{H}_{14}{ }^{+}$, and $\mathrm{H}_{20}{ }^{+}$in a hollow electron beam that traps positive ions; the absence of other evennumbered cluster ions and the low mass resolution render this observation questionable. Recent reports on evennumbered $\mathrm{D}_{n}^{+}$up to $n=12$ (Ref. 27) and 14 (Ref. 28) formed upon electron-impact ionization of free deuterium clusters are not conclusive either because of the low mass resolution. ${ }^{52}$

The most compelling identification of even-numbered hydrogen cluster ions so far was reported by Kirchner and Bowers ${ }^{53}$ who produced $\mathrm{H}_{4}{ }^{+}, \mathrm{H}_{6}{ }^{+}, \mathrm{H}_{8}{ }^{+}$, and $\mathrm{H}_{10}{ }^{+}$in a highpressure drift-tube ion source and identified them by highresolution mass spectrometry. $\mathrm{H}_{6}{ }^{+}$was the most intense even-numbered cluster ion $\left(5 \%\right.$ of $\left.\mathrm{H}_{5}{ }^{+}\right) . \mathrm{H}_{8}{ }^{+}$and $\mathrm{H}_{10}{ }^{+}$were at least an order of magnitude weaker than $\mathrm{H}_{6}^{+}$, and $\mathrm{H}_{4}{ }^{+}$was weaker by another two orders of magnitude.

We report here the synthesis of even-numbered $\mathrm{H}_{n}{ }^{+}$at much higher yield, and much larger in size, by electronimpact ionization of neutral hydrogen clusters embedded in ultracold helium droplets. Even though helium is in many respects an ideal matrix because it minimizes solventinduced perturbations, it does affect the reaction dynamics that are initiated by ionization. ${ }^{54-56}$ We attribute the observed increase in the relative yield of even-numbered cluster ions to a caging effect; rapid escape of a hyperthermal hydrogen atom from the highly excited hydrogen cluster ion is suppressed by impulsive collisions with the surrounding helium atoms. The high-resolution mass spectrometer allows pure $\mathrm{H}_{n}{ }^{+}$to be distinguished from other ions that have the same nominal mass-to-charge ratio. For example, at $m / q=20 \mathrm{Th}$ we observe, and resolve, $\mathrm{He}_{5}^{+}, \mathrm{He}_{4} \mathrm{H}_{4}^{+}, \mathrm{He}_{3} \mathrm{H}_{8}{ }^{+}, \mathrm{He}_{2} \mathrm{H}_{12}{ }^{+}$, $\mathrm{HeH}_{16}{ }^{+}, \mathrm{H}_{20}{ }^{+}$, and ${ }^{40} \mathrm{Ar}^{2+}$ (see Fig. 1). The relatively large intensity of the observed even-numbered cluster ions excludes contamination from deuterated species, and the abundance of mixed helium-hydrogen cluster ions is minimized by optimizing the cluster source conditions. We are thus able to identify pure even-numbered $\mathrm{H}_{n}{ }^{+}$up to $n \cong 120$, greatly exceeding the previous limit of $n=10$ (Ref. 53) beyond which computed binding energies become extremely small. ${ }^{57}$ In addition to the previously reported abundance maximum at $\mathrm{H}_{6}{ }^{+}$we observe anomalies at $n=30$ and 114 , which we tentatively assign to icosahedral shell closures at $\mathrm{H}_{6}{ }^{+}\left(\mathrm{H}_{2}\right)_{12}$ and $\mathrm{H}_{6}{ }^{+}\left(\mathrm{H}_{2}\right)_{54}$. The structure of the presumed cluster core, $\mathrm{H}_{6}{ }^{+}$, is explored at the quadratic configuration interaction with inclusion of single and double excitations (QCISD)/ aug-cc-pVTZ level of theory.

\section{EXPERIMENTAL SECTION}

Measurements are performed with a He cluster source, a pickup cell containing the hydrogen gas, a conventional Nier-type electron source for electron ionization, and a highresolution two-sector field magnetic mass spectrometer. Details have been described elsewhere. ${ }^{58-61}$ Neutral helium droplets are formed by expansion of helium gas at a pressure of 22 bar into vacuum through a nozzle with an orifice of $5 \mu \mathrm{m}$ and adjustable temperature. In this work the tempera-

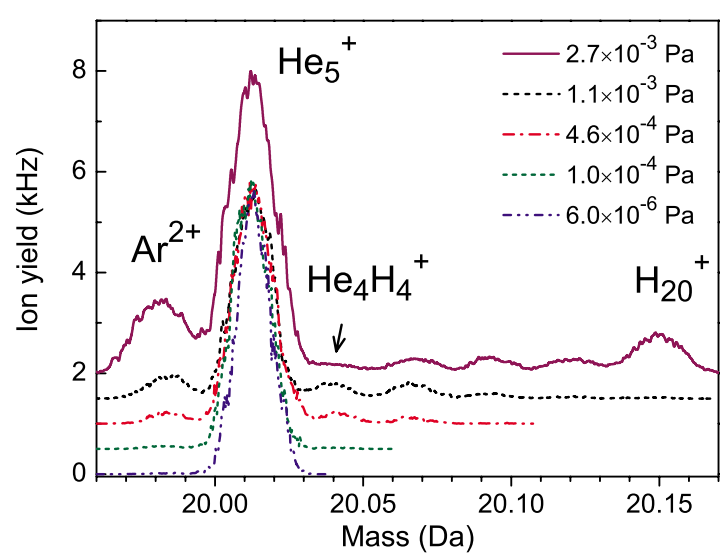

FIG. 1. (Color online) Mass spectra of ions near $m \cong 20$ Da recorded with different hydrogen pressures in the pickup cell. The spectra are displaced vertically for greater clarity. $\mathrm{He}_{5}{ }^{+}$and nominally isobaric $\mathrm{He}_{4} \mathrm{H}_{4}{ }^{+}, \mathrm{He}_{3} \mathrm{H}_{8}{ }^{+}$, $\mathrm{He}_{2} \mathrm{H}_{12}{ }^{+}, \mathrm{HeH}_{16}{ }^{+}$, and $\mathrm{H}_{20}{ }^{+}$are clearly resolved; an argon impurity gives rise to ${ }^{40} \mathrm{Ar}^{2+} \cdot \mathrm{H}_{20}{ }^{+}$dominates at highest hydrogen pressure.

ture was set to $9.5 \mathrm{~K}$; the mean size of the helium droplets is estimated to be a few $10^{4}{ }^{62} 1 \mathrm{~cm}$ downstream from the nozzle, the droplets pass a skimmer with a diameter of 0.8 $\mathrm{mm} .2 \mathrm{~cm}$ further downstream, they enter a pickup cell, kept at ambient temperature, where they are doped with molecular hydrogen (nominal purity of $99.999 \%$ ). The electron source of the mass spectrometer (Varian MAT CH5-DF of the reversed Nier-Johnson-type $B-E$ geometry) is operated at a current of $10 \mu \mathrm{A}$ and an energy resolution of about $1 \mathrm{eV}$. Electron energies are either 110 or $200 \mathrm{eV}$; values are specified in the text. The base pressure in the ion source is 2 $\times 10^{-5} \mathrm{~Pa}$. Cations are extracted from the ion source by a weak electric field through a potential drop of $3 \mathrm{kV}$ into the mass spectrometer. In the present work, the resolving power was $m / \Delta m \cong 1000$ ( $\Delta m=$ full width at half maximum).

\section{RESULTS}

\section{A. Experimental results}

Even-numbered hydrogen cluster ions are readily observed in mass spectra of helium droplets doped with hydrogen. Their unambiguous identification by high-resolution mass spectrometry is demonstrated by the spectra in Fig. 1, which were recorded with an electron energy of $200 \mathrm{eV}$ and various pressures of hydrogen in the pickup cell. Near mass $20 \mathrm{Da}$ we observe the series $\mathrm{He}_{5-x} \mathrm{H}_{4 x}{ }^{+}$with $0 \leq x \leq 5 .{ }^{63}$ The mass difference between adjacent ions in this series is $m_{\mathrm{He}}-4 m_{\mathrm{H}}=0.0287 \mathrm{Da}^{65}$ At the highest hydrogen pressure the intensity of $\mathrm{H}_{20}{ }^{+}$clearly exceeds that of mixed $\mathrm{He}_{5-x} \mathrm{H}_{4 x}{ }^{+}$ ions.

Ion series qualitatively similar to the one shown in Fig. 1 are observed around 21,22 , and $23 \mathrm{Da}$. The heaviest isotopomers in these series correspond to $\mathrm{H}_{21}{ }^{+}, \mathrm{H}_{22}{ }^{+}$, and $\mathrm{H}_{23}{ }^{+}$, respectively. Other peaks in the series are due to mixed helium-hydrogen complexes. The series demonstrate that even-numbered as well as odd-numbered hydrogen cluster ions can be formed with helium atoms attached to them.

Two other sections of mass spectra are reproduced in Fig. 2; they further illustrate the identification of even- 


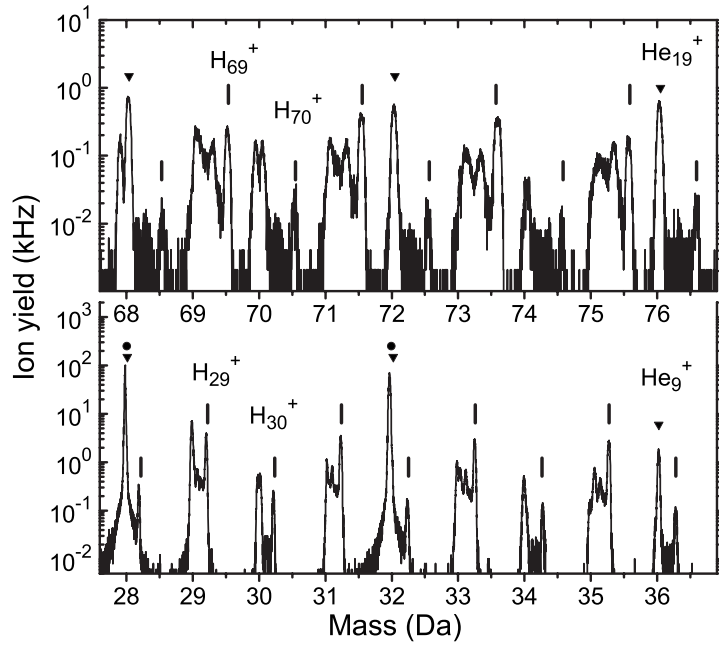

FIG. 2. Sections of mass spectra showing odd- and even-numbered $\mathrm{H}_{n}{ }^{+}$ (vertical lines), $\mathrm{He}_{n}^{+}$(triangles), and impurities $\mathrm{N}_{2}^{+}$and $\mathrm{O}_{2}^{+}$(full dots) Other mass peaks, immediately to the left of $\mathrm{H}_{n}{ }^{+}$, are mostly due to mixed $\mathrm{He}_{x} \mathrm{H}_{y}{ }^{+}$and hydrocarbon background.

numbered $\mathrm{H}_{n}^{+}$. Background ions $\left(\mathrm{N}_{2}^{+}, \mathrm{O}_{2}^{+}\right.$, marked by full dots) and $\mathrm{He}_{n}^{+}$(triangles) provide an accurate mass calibration. Vertical lines indicate the expected position of $\mathrm{H}_{n}^{+} \mathrm{cal}$ culated from this calibration. Thanks to the large mass excess of $\mathrm{H}(1.007825 \mathrm{Da})$, all but the very smallest $\mathrm{H}_{n}^{+}$ cluster ions are well separated from hydrocarbon ions whose masses are close to integer values.

The mass resolution is not sufficient to distinguish deuterated cluster ions $\mathrm{H}_{n-2} \mathrm{D}^{+}$from undeuterated species $\mathrm{H}_{n}^{+}$, which are heavier by $0.00155 \mathrm{Da}$. However, the low $(0.015 \%)$ natural abundance of $\mathrm{D}$ excludes any significant contributions to our data. For example, the statistical ratio of $\mathrm{H}_{28} \mathrm{D}^{+}: \mathrm{H}_{29}{ }^{+}$would be $0.4 \%$, whereas the observed abundance ratio $\mathrm{H}_{30}{ }^{+}: \mathrm{H}_{29}{ }^{+}$is $5 \%$. Another hint against the contribution of deuterated species to our spectra is the approximately constant abundance ratio between even- and oddnumbered cluster ions. In contrast, the statistical probability that $\mathrm{H}_{n-2} \mathrm{D}^{+}$contributes to $\mathrm{H}_{n}^{+}$would increase with size $n$.

We have recorded several other mass spectra of hydrogen clusters. One set, measured with a hydrogen pressure of $5 \times 10^{-3} \mathrm{~Pa}$ and an electron energy of $110 \mathrm{eV}$, was carefully analyzed by fitting Gaussians to all relevant mass peaks. From this analysis we obtain the size distribution of $\mathrm{H}_{n}^{+}$ presented in Fig. 3. The upper panel displays the distribution of even-numbered cluster ions. We note a maximum at $\mathrm{H}_{6}{ }^{+}$ and an abrupt drop beyond $\mathrm{H}_{30}{ }^{+}$. The full distribution of odd and even sizes is shown on a logarithmic scale in the lower panel. The statistical significance of local intensity anomalies between $n=35$ and 93 has not yet been confirmed. However, an abrupt drop in the distribution of even-numbered cluster ions at $n=114$ is significant; it will be discussed in Sec. IV. The abundance of even-numbered cluster ions relative to the next smaller odd-numbered cluster ions average $4 \%$. For $\mathrm{H}_{6}^{+}$ versus $\mathrm{H}_{5}{ }^{+}$the ratio reaches a value of $11 \%$, a factor 2 larger than reported by Kirchner and Bowers. ${ }^{53}$

The ion yield curve of $\mathrm{H}_{6}^{+}$versus electron energy presented in Fig. 4 shows an onset near the threshold for production of metastable $\mathrm{He}^{*}(20.6 \mathrm{eV})$, and an increase in its

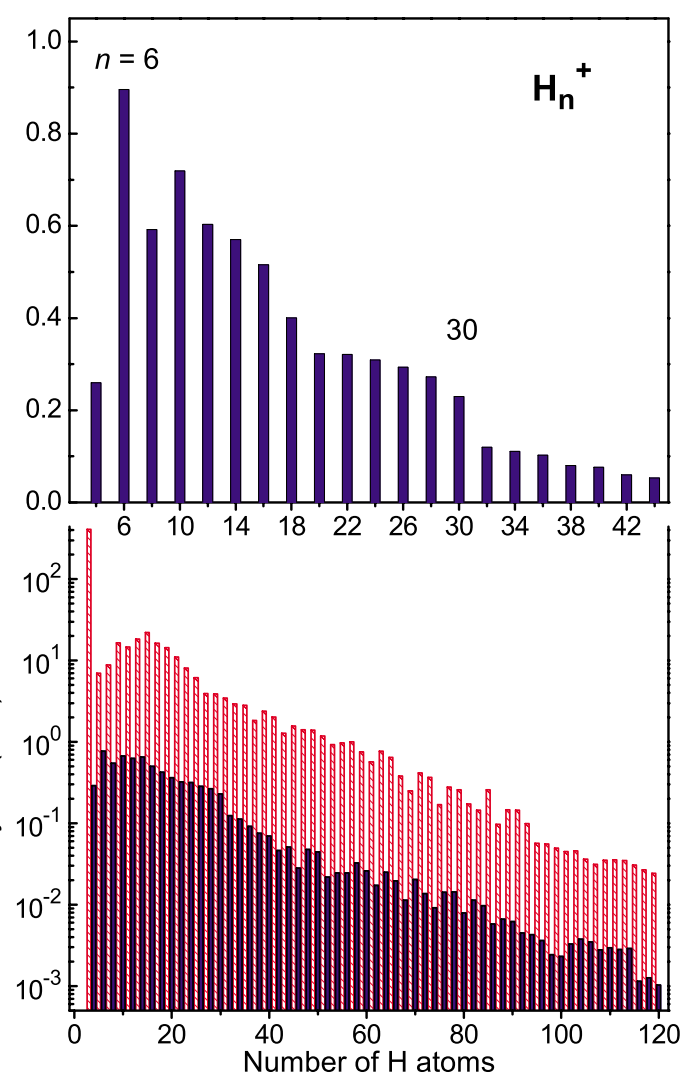

FIG. 3. (Color online) Upper panel: Size distribution of even-numbered hydrogen cluster ions. Lower panel: Size distribution of even-numbered (solid bars) and odd-numbered (dashed bars) hydrogen cluster ions plotted on a logarithmic scale.

slope at the ionization energy of helium $(24.56 \mathrm{eV}) .^{30}$ Thus, the Penning ionization as well as charge transfer from $\mathrm{He}^{+}$ contribute to the $\mathrm{H}_{6}{ }^{+}$ion yield. Direct ionization of hydrogen clusters would feature a lower onset because the adiabatic ionization energy of $\mathrm{H}_{2}$ is only $15.428 \mathrm{eV}^{27,30}$ its contribution is below the detection limit. This observation agrees with experiments on other clusters embedded in helium droplets which show that direct ionization is extremely inefficient. ${ }^{62,66,67}$

For the interpretation of the observed magic numbers $n=30$ and 114 , the nature of the presumed ionic core, $\mathrm{H}_{6}{ }^{+}$, is

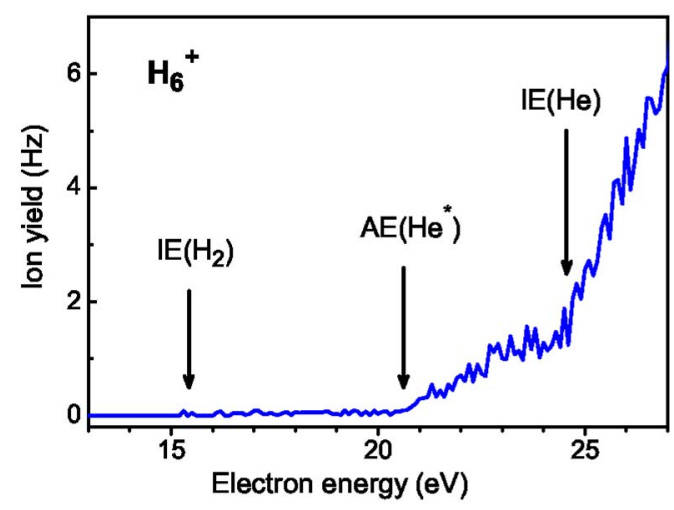

FIG. 4. (Color online) Ion yield of $\mathrm{H}_{6}{ }^{+}$as a function of electron energy recorded at a hydrogen pressure of $2.7 \times 10^{-3} \mathrm{~Pa}$. Energy thresholds for the formation of $\mathrm{H}_{2}^{+}, \mathrm{He}^{*}$, and $\mathrm{He}^{+}$are indicated. 


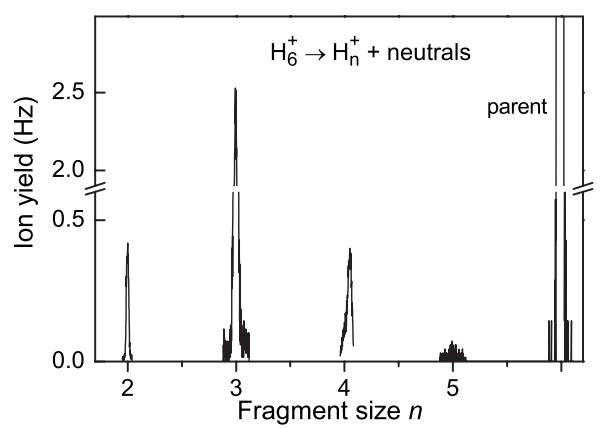

FIG. 5. Metastable dissociation of $\mathrm{H}_{6}{ }^{+}$into $\mathrm{H}_{2}{ }^{+}, \mathrm{H}_{3}{ }^{+}, \mathrm{H}_{4}{ }^{+}$, and $\mathrm{H}_{5}{ }^{+}$in the second field free region of the two-sector-field mass spectrometer (MIKE scan). Spontaneous (unimolecular) as well as collision-induced reactions contribute to the signal.

of relevance. ${ }^{57}$ We explore its dissociation channels by recording mass analyzed ion kinetic energy (MIKE) spectra. $\mathrm{H}_{6}{ }^{+}$is selected by the magnet; its metastable dissociation into fragment ions in the second field free region between the magnetic and electric sector is measured by scanning the electric sector field voltage. The pressure in the second field free region is slightly below $1 \times 10^{-5} \mathrm{~Pa}$; thus the MIKE spectrum may contain contributions from collision-induced fragmentation of $\mathrm{H}_{6}{ }^{+68}$.

A MIKE spectrum is displayed in Fig. 5. The major product ion is $\mathrm{H}_{3}{ }^{+}$; its metastable fraction (i.e., the ratio of its intensity to the intensity of the parent ion) is $1.4 \times 10^{-5} \cdot \mathrm{H}_{2}^{+}$ is weaker by a factor $6 . \mathrm{H}_{4}^{+}$(that merges into a much stronger satellite peak caused by interference with another decay channel ${ }^{69,70}$ ) and $\mathrm{H}_{5}{ }^{+}$are weaker by another order of magnitude. From the width of the $\mathrm{H}_{3}{ }^{+}$peak we deduce ${ }^{71}$ an average kinetic energy release $\langle\mathrm{KER}\rangle=57 \pm 2 \mathrm{meV}$ assuming onestep dissociation into $\mathrm{H}_{3}{ }^{+}+\mathrm{H}_{3}$ (we cannot identify neutral products). It is more likely that the reaction proceeds in two distinct steps, emission of a $\mathrm{H}$ atom followed by loss of $\mathrm{H}_{2}{ }^{32}$ In this case, the measured width of the $\mathrm{H}_{3}^{+}$fragment ion peak would correspond to a slightly larger $\langle\mathrm{KER}\rangle$.

\section{B. $\mathrm{H}_{6}^{+}$}

From an early $a b$ initio study, Wright and Borkman ${ }^{72}$ concluded that $\mathrm{H}_{6}{ }^{+}$consists of a nearly equilateral $\mathrm{H}_{3}{ }^{+}$core surrounded by neutral $\mathrm{H}$ and $\mathrm{H}_{2}$ at two of its apices $\left(C_{s}\right.$ symmetry); the ion was bound with respect to $\mathrm{H}_{5}{ }^{+}+\mathrm{H}$ by only $0.05 \mathrm{eV}$. However, Montgomery and Michels ${ }^{73}$ identified a more stable isomer consisting of a central $\mathrm{H}_{2}{ }^{+}$weakly bound to two $\mathrm{H}_{2}$ molecules $\left(D_{2 d}\right)$. More recently, Kurosaki and Takayanagi ${ }^{74}$ optimized the geometries of $\mathrm{H}_{6}{ }^{+}$at the MP2/cc-pVTZ level of theory ${ }^{75,76}$ and calculated MP4 (Møller-Plesset perturbation theory including single to quadruple excitations) ${ }^{77,78}$ energies. They found that the $D_{2 d}$ structure lies $0.17 \mathrm{eV}$ below $C_{s}$; the latter is separated from the ground state configuration by a small $(0.02 \mathrm{eV})$ barrier. The $D_{2 d}$ structure has been confirmed in an electron spin resonance study of hydrogen ion radicals produced by radiolysis of solid parahydrogen. ${ }^{79}$ The two outer $\mathrm{H}_{2}$ molecules were found to rotate almost freely, in agreement with a path integral molecular dynamics study. ${ }^{80}$

We have searched the $\mathrm{H}_{6}^{+}$potential energy surface for other possible isomers that might serve as cores for the coordination of additional $\mathrm{H}_{2}$ molecules. We did this by generating both regular structures and random structures. The sample of about 30 configurations was optimized at the QCISD (Ref. 81)/aug-cc-pVTZ (Refs. 82 and 83) level of theory, probably the most accurate level used on these systems so far.

Our geometries converged to the six minima on the potential energy surface shown in Fig. 6. The $C_{s}$ isomer (S2) lies $0.15 \mathrm{eV}$ above the lowest-energy structure $\left(\mathrm{S} 1, D_{2 d}\right)$ in good agreement with the value $(0.17 \mathrm{eV})$ calculated by Kurosaki and Takayanagi. ${ }^{74}$ The Mulliken and natural population analysis (NPA) of partial charges and spin populations listed in Table I show that the positive charge in S1 is quite delocalized, in agreement with a previous study. ${ }^{57}$ In contrast, in S2 the positive charge is mostly concentrated on the $\mathrm{H}_{3}{ }^{+}$core which is very weakly bound to the outer $\mathrm{H}_{2}$ and $\mathrm{H}$.

Structure S3 is only slightly higher in energy than S2. It

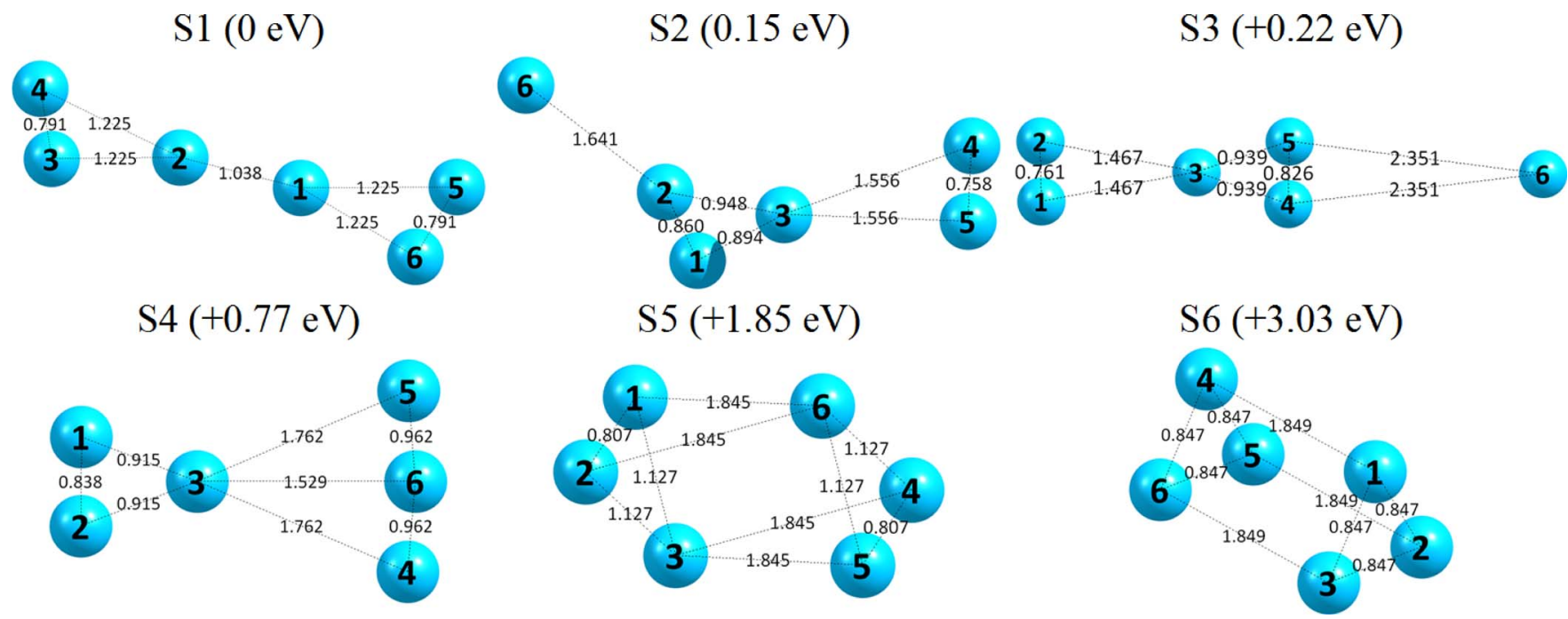

FIG. 6. (Color online) Six minima and their energies relative to the most stable one (isomer $\mathrm{S} 1$ ) on the potential energy surface of $\mathrm{H}_{6}^{+}$, computed at the QCISD/aug-cc-pVTZ level of theory. Bond lengths are in angstroms. 
TABLE I. Mulliken and NPA partial charges and spin populations (HF/aug-cc-pVTZ calculations). Numbers in the first column specify the $\mathrm{H}$ atom, see Fig. 6. Structural data may be obtained from the authors upon request.

\begin{tabular}{|c|c|c|c|c|c|c|c|c|c|c|c|c|c|c|c|c|c|c|}
\hline \multirow[b]{2}{*}{$\mathrm{H}$} & \multicolumn{3}{|c|}{$\mathrm{S} 1\left(D_{2 d}\right)$} & \multicolumn{3}{|c|}{$\mathrm{S} 2\left(C_{s}\right)$} & \multicolumn{3}{|c|}{$\mathrm{S} 3\left(C_{2 v}\right)$} & \multicolumn{3}{|c|}{$\mathrm{S} 4\left(C_{2 v}\right)$} & \multicolumn{3}{|c|}{ S5 $\left(C_{2 h}\right)$} & \multicolumn{3}{|c|}{$\mathrm{S} 6\left(D_{3 h}\right)$} \\
\hline & MULL & NPA & SPIN & MULL & NPA & SPIN & MULL & NPA & SPIN & MULL & NPA & SPIN & MULL & NPA & SPIN & MULL & NPA & SPIN \\
\hline 1 & 0.32 & 0.20 & 0.29 & 0.39 & 0.24 & 0.03 & 0.07 & 0.06 & 0.00 & 0.44 & 0.28 & 0.00 & 0.18 & 0.15 & 0.01 & 0.29 & 0.32 & 0.00 \\
\hline 2 & 0.32 & 0.20 & 0.29 & 0.13 & 0.25 & 0.05 & 0.07 & 0.06 & 0.00 & 0.45 & 0.28 & 0.00 & 0.18 & 0.15 & 0.01 & 0.11 & 0.09 & 0.26 \\
\hline 3 & 0.09 & 0.15 & 0.11 & 0.31 & 0.32 & 0.02 & 0.18 & 0.33 & 0.00 & 0.00 & 0.34 & 0.00 & 0.15 & 0.19 & 0.44 & 0.11 & 0.09 & 0.26 \\
\hline 4 & 0.09 & 0.15 & 0.11 & 0.05 & 0.05 & 0.00 & 0.34 & 0.26 & 0.02 & -0.04 & 0.13 & 0.60 & 0.18 & 0.15 & 0.03 & 0.29 & 0.32 & 0.00 \\
\hline 5 & 0.09 & 0.15 & 0.11 & 0.05 & 0.05 & 0.00 & 0.34 & 0.26 & 0.02 & -0.04 & 0.13 & 0.60 & 0.18 & 0.15 & 0.03 & 0.11 & 0.09 & 0.26 \\
\hline 6 & 0.09 & 0.15 & 0.11 & 0.08 & 0.10 & 0.90 & 0.01 & 0.01 & 0.97 & 0.18 & -0.17 & -0.19 & 0.15 & 0.19 & 0.44 & 0.11 & 0.09 & 0.26 \\
\hline
\end{tabular}

may be best characterized as $\mathrm{H}_{5}^{+}+\mathrm{H}$. It is not quite a symmetric variation of $\mathrm{S} 2$ because the single $\mathrm{H}$ is further away from the central $\mathrm{H}_{3}$ unit. A structure consisting of one linear and one triangular $\mathrm{H}_{3}$ unit (S4) as well as the trigonal antiprismatic (S5) and prismatic (S6) structures are all significantly higher in energy than S3. Whereas S1-S4 are true locally stable isomers, S5 and S6 are stable only when confined to their symmetries $\left(C_{2 h}\right.$ and $D_{3 h}$, respectively).

\section{DISCUSSION}

Although the thermodynamic stability of even-numbered hydrogen cluster ions already was pointed out by Wright and Borkman $^{72}$ in 1982, these species have, with the exception of $\mathrm{H}_{6}{ }^{+53,79}$ largely escaped experimental identification. The main reason for the difficulty of identifying even-numbered $\mathrm{H}_{n}{ }^{+}$in mass spectra of hydrogen clusters is the fact that a large fraction of the energy that is released upon vertical ionization is transferred to a hydrogen atom that will thus leave the ionized complex within $<1$ ps. ${ }^{32}$ Another, more technical problem is the presence of deuterium; clusters $\mathrm{H}_{n-2} \mathrm{D}^{+}$with an odd number of atoms may easily be mistaken for even-numbered $\mathrm{H}_{n}{ }^{+}$because both have the same nominal mass, $n$ Da. An analogous problem applies to experiments with deuterium clusters contaminated with traces of ${ }^{1} \mathrm{H} \cdot{ }^{27,28}$

In the present study we were able to use a highresolution mass spectrometer to identify even-numbered $\mathrm{H}_{n}^{+}$ up to $n=120$. Two factors made this possible: First, the high mass resolution easily distinguishes $\mathrm{H}_{n}^{+}$from most background ions, helium cluster ions, and mixed $\mathrm{He}_{x} \mathrm{H}_{y}{ }^{+}$. The large mass excess of the hydrogen atom $(1.007825 \mathrm{Da})$ separates $\mathrm{H}_{n}{ }^{+}$from hydrocarbons $\mathrm{C}_{x} \mathrm{H}_{y}{ }^{+}$up to $n \cong 128$, where the mass of $\mathrm{H}_{n}{ }^{+}$again approaches integer values $n+1 \mathrm{Da}$. Second, the hydrogen clusters are grown in helium nanodroplets. An ab initio direct dynamics calculation indicates that a free hydrogen cluster such as $\mathrm{H}_{6}$ will, upon vertical ionization, eject a hydrogen atom within $\approx 100 \mathrm{fs}$; the atom will carry a substantial fraction of the reaction energy. ${ }^{32}$ Hence, in order to enhance the relative yield of evennumbered cluster ions formed in a helium droplet, the matrix will have to suppress the separation of the hydrogen atom from the charged complex within the first $100 \mathrm{fs}^{84}$ This kind of rapid energy exchange between the nascent evennumbered hydrogen cluster ion and the helium matrix is akin to the impulsive processes that are responsible for caging of photoexcited $\mathrm{I}_{2}^{-}$and $\mathrm{HCl}$ in inert gas clusters. ${ }^{85-87} \mathrm{In}$ this context it is worth mentioning that the first observation of unprotonated water cluster ions $\left(\mathrm{H}_{2} \mathrm{O}\right)_{n}{ }^{+}$was achieved by synthesizing neutral water clusters complexed with argon atoms, ${ }^{88}$ and later by embedding water clusters in helium droplets. ${ }^{67,89-91}$ We also note that ionization of molecules embedded in helium is a multistep process. ${ }^{92}$ First a helium cation is formed; after rapid charge migration the cation transfers the charge to the molecule. A large amount of energy is released in the process. Nevertheless, dissociation of the nascent molecular cations will, under certain conditions, be strongly quenched by the helium matrix. ${ }^{93,94}$

However, one should note that the vibrational excitation energy in the observed cluster ions, even- and odd-numbered alike, is not necessarily low. The neutral precursors are clearly cold, at a rovibrational temperature of $0.37 \mathrm{~K}$, because they form inside helium droplets. ${ }^{95}$ Figure 1 demonstrates that under certain source conditions we can form hydrogen cluster ions that are quite cold as well else they would not form long-lived complexes with helium. However, the abundance spectrum in Fig. 3 is deduced from hydrogen cluster ions that are not complexed with $\mathrm{He}$, see Fig. 2. An upper bound to their temperature may be estimated from the evaporative model. ${ }^{96}$ Essentially, the temperature of a freely evaporating cluster of modest $\operatorname{size}^{97}$ will be proportional to its evaporation energy. Once the first solvation shell is filled, the evaporation energies of charged and neutral clusters will be similar. Comparison with expected and measured temperatures ${ }^{98}$ of neutral neon, argon, and other clusters leads to an estimate of $\cong 10 \mathrm{~K}$ for the temperature of $\mathrm{H}_{n}^{+}$, $n>30$, in our experiment.

Cluster ions with helium atoms attached will be colder whereas small, pure hydrogen cluster ions may be warmer. When molecular complexes embedded in helium droplets are ionized, the major products are usually molecular ions (or fragment ions) with no, or very few, helium attached. ${ }^{99}$ These ions cannot form by complete vaporization of the helium unless the initial droplet is exceedingly small (the binding energy of helium is $0.616 \mathrm{meV}$ per atom in the bulk; hence no more than 2000 atoms can be evaporated for every $1 \mathrm{eV}$ of excess energy). Rather, the bare molecular ions formed are ejected from the droplet in an athermal process. Therefore it is not surprising that the $\mathrm{H}_{6}{ }^{+}$ions formed in the present study may carry sufficient vibrational energy to undergo spontaneous (unimolecular) dissociation about $5 \mu \mathrm{s}$ after their formation and thus contribute to the MIKE spectrum, Fig. 5. The spectrum differs strikingly from the spec- 
trum reported by Kirchner and Bowers, ${ }^{53}$ they found $\mathrm{H}_{5}{ }^{+}$and $\mathrm{H}_{4}{ }^{+}$as the major metastable product ions of $\mathrm{H}_{6}{ }^{+}$. They separated the contributions from spontaneous (unimolecular) and collision-induced dissociation, and deduced branching ratios of 80:20 for the former and 40:60 for the latter. The average KER for dissociation into $\mathrm{H}_{5}{ }^{+}+\mathrm{H}$ was $38 \mathrm{meV}$.

What causes the striking differences between our MIKE spectra and those reported by Kirchner and Bowers? ${ }^{53}$ We can imagine three reasons. First, the parent ions are produced in fundamentally different ways; ${ }^{68}$ the differences will affect the excitation energies in the metastable ions, perhaps also their geometric structure. Second, both studies employed two-sector-field magnetic mass spectrometers. These instruments are able to mass-resolve $\mathrm{H}_{4} \mathrm{D}^{+}$and $\mathrm{H}_{6}{ }^{+}$ions ${ }^{53}$ but the resolution is greatly diminished in the MIKE mode, ${ }^{100}$ and $\mathrm{H}_{4} \mathrm{D}^{+}$may contaminate the metastable spectrum of $\mathrm{H}_{6}{ }^{+}$. Third, collision-induced reactions may contribute to the metastable ion signal. We cannot separate the contributions of collision-induced and unimolecular reactions although the rather large metastable fraction of $\mathrm{H}_{3}{ }^{+}$suggests that this ion is mostly due to unimolecular dissociation. Even more compelling, neither unimolecular nor collision-induced reactions are found to favor the $\mathrm{H}_{3}{ }^{+}$product ion, ${ }^{53}$ thus reason 3 cannot account for the observations. In our view, the most likely explanation is due to differences in the geometric structure of the $\mathrm{H}_{6}{ }^{+}$ions. Unfortunately, not enough is known about reaction paths and critical energies for isomerization and dissociation of $\mathrm{H}_{6}^{+}$; hence we refrain from further discussion of this topic.

An intriguing observation in Fig. 3 is the abrupt drop in the abundance of even-numbered $\mathrm{H}_{n}{ }^{+}$beyond $n=30$ and 114 indicating geometric shell closures. Evidence for shellclosings in odd-numbered hydrogen cluster ions has previously been concluded from theoretical studies. $36,38,41,42,48$ These clusters consist of a tightly bound $\mathrm{H}_{3}{ }^{+}$core surrounded by $\mathrm{H}_{2}$ and are therefore best described as $\mathrm{H}_{3}{ }^{+}\left(\mathrm{H}_{2}\right)_{m}$. The first, mainly chemically bonded solvation shell closes at $m=3$ and the second, mostly physically bonded shell at $m=15$. Anomalies in cluster ion size distributions, ${ }^{24,25,28}$ collisional dissociation cross sections, ${ }^{101,102}$ thermochemical stability, ${ }^{103}$ and IR absorption spectra ${ }^{104}$ lend support to the existence of geometric shells but entropic effects may also play a role. ${ }^{44}$

The magic numbers observed in the present work for even-numbered clusters are different. Can they be related to a structural model? In the absence of directional bonding and electronic shell effects ${ }^{105}$ one frequently observes geometric shell closure when the number of building blocks reaches $m=12$ in the first icosahedral shell around the ionic core, $m=42$ in the second, $m=92$ in the third, and so on. ${ }^{106-109}$ The numbers may be slightly different depending on the exact nature of the ionic core (see Refs. 110-112 and references therein) but they readily appear for inert gas clusters ${ }^{113,114}$ as well as molecular clusters of $\mathrm{CO}$ and $\mathrm{CH}_{4}{ }^{115,116}$ The observed magic numbers $n=30$ and 114 do indeed match the number of hydrogen atoms needed to complete icosahedral shells around $\mathrm{a}_{6}{ }^{+}$core; they correspond to cluster ions $\mathrm{H}_{6}^{+}\left(\mathrm{H}_{2}\right)_{12}$ and $\mathrm{H}_{6}^{+}\left(\mathrm{H}_{2}\right)_{12}\left(\mathrm{H}_{2}\right)_{42}$.

While our $a b$ initio calculations have identified some possible new isomers of $\mathrm{H}_{6}{ }^{+}$, they failed to reveal a low- lying compact isomer that could be solvated symmetrically by an icosahedral shell of $\mathrm{H}_{2}$ molecules. Of course, our calculations deal with the potential energy surface while the quantum nature of the $\mathrm{H}$ atoms must also be taken into account. Nevertheless, a recent path integral molecular dynamics simulation of $\mathrm{H}_{6}{ }^{+}$- and $\mathrm{D}_{6}{ }^{+}$-clusters indicates that the delocalization of $\mathrm{H}$ is not so large as to make classical structures meaningless, although it certainly must be considered for quantitative discussions. ${ }^{80}$ One would also have to consider the finite temperature of cluster ions in the experiment which we have estimated above at $10 \mathrm{~K}$.

We are aware of only one theoretical study of evennumbered clusters larger than $\mathrm{H}_{6}^{+}$, the ab initio moleculardynamics molecular MO study of $\mathrm{H}_{n}{ }^{+}(n=6,8,10,12,14)$ by Kurosaki and Takayanagi. ${ }^{57}$ Interestingly, they found that the $D_{2 d}$ isomer of $\mathrm{H}_{6}{ }^{+}$remains the lowest isomer for all cluster sizes even though the energy difference between isomers S2 $\left(C_{s}\right)$ and $\mathrm{S} 1\left(D_{2 d}\right)$ decreases. The $\mathrm{H}_{2}$ ligands are weakly bound to the four corners of the nearly unperturbed $\mathrm{H}_{6}{ }^{+}$. The binding energy of the $\mathrm{H}_{2}$ ligands becomes extremely small with increasing size; for $\mathrm{H}_{14}{ }^{+}$it is within the computational uncertainty of $0.05 \mathrm{eV}$. Ab initio studies of larger clusters at higher accuracy will be needed to corroborate our interpretation of the observed magic numbers at $n=30$ and 114 in terms of icosahedral shell closure.

\section{CONCLUSION}

The experimental results reported here demonstrate that large even-numbered $\mathrm{H}_{n}{ }^{+}$can be formed by electron-impact ionization of hydrogen clusters embedded in helium nanodroplets. The abundance of even-numbered cluster ions relative to the next smaller odd-numbered cluster ions is quite large, $4 \%$ on average. With the use of high-resolution mass spectrometry we were able to greatly extend the size range over which even-numbered $\mathrm{H}_{n}{ }^{+}$can be unambiguously identified, from $n=10$ to $n=120$.

Our mass spectra reproduce the enhanced stability of $\mathrm{H}_{6}{ }^{+}$previously reported by Kirchner and Bowers ${ }^{53}$ under completely different experimental conditions. On the other hand, the reaction channels observed for metastable dissociation of $\mathrm{H}_{6}{ }^{+}$differ significantly from the earlier report. Our $a b$ initio study at the QCISD/aug-cc-pVTZ level of theory reproduces the two lowest isomers at $\mathrm{H}_{6}^{+}$reported previously, ${ }^{73,74}$ identifies another one only slightly higher than the $C_{s}$ isomer, and three others at significantly higher energies.

Intriguing drops in the ion abundance at $n=30$ and 114 suggest shell closures for $\mathrm{H}_{6}{ }^{+}\left(\mathrm{H}_{2}\right)_{12}$ and $\mathrm{H}_{6}{ }^{+}\left(\mathrm{H}_{2}\right)_{54}$, equivalent to icosahedral shell closures observed for $\mathrm{Xe}_{13}{ }^{+}, \mathrm{Xe}_{55}{ }^{+}$, and several other atomic and molecular van der Waals bound cluster ions. ${ }^{107-109,117,118}$ This interpretation is consistent with theoretical results which show that the $D_{2 h}$ ground state isomer of $\mathrm{H}_{6}{ }^{+}$is nearly unperturbed when complexed with up to four $\mathrm{H}_{2}$ molecules. ${ }^{57} \mathrm{Ab}$ initio studies of larger cluster ions will be needed to confirm our interpretation of icosahedral shells. We note that magic number effects in neutral parahydrogen clusters $\left(\mathrm{H}_{2}\right)_{n}$ have recently attracted attention. Experiment $^{19}$ as well as theory ${ }^{11,13,14,119}$ indicate the presence 
of geometric shells in these quantum systems. The coexistence of superfluid and solidlike phases at ultralow temperatures is not an impediment to the existence of particularly compact, stable cluster sizes.

\section{ACKNOWLEDGMENTS}

S.D. gratefully acknowledges an APART grant from the Austrian Academy of Sciences. This work was supported by the FWF, Wien, Austria, and the European Commission, Brussels (project ITS LEIF).

${ }^{1}$ R. Klingelhöfer and H. O. Moser, J. Appl. Phys. 43, 4575 (1972).

${ }^{2}$ E. W. Becker, O. F. Hagena, P. R. W. Henkes, W. Keller, R. Klingelhöfer, B. Krevel, and H. O. Moser, Nucl. Eng. Des. 73, 187 (1982).

${ }^{3}$ L. Yao, B. Feng, J. Dong, Y. Zhou, Z. Cui, J. Cao, N. Tang, Z. Feng, Z. Xiao, X. Song, W. Hong, E. Wang, and Y. Liu, Fusion Sci. Technol. 42 107 (2002).

${ }^{4}$ J. Yiming, Z. Yan, Y. Lianghua, and D. Jiaqi, Plasma Phys. Controlled Fusion 45, 2001 (2003).

${ }^{5}$ T. Ditmire, J. Zweiback, V. P. Yanovsky, T. E. Cowan, G. Hays, and K. B. Wharton, Nature (London) 398, 489 (1999).

${ }^{6}$ F. Pauzat and Y. Ellinger, Planet. Space Sci. 53, 1389 (2005).

${ }^{7}$ O. Mousis, F. Pauzat, Y. Ellinger, and C. Ceccarelli, Astrophys. J. 673, 637 (2008).

${ }^{8}$ D. Gerlich, E. Herbst, and E. Roue, Planet. Space Sci. 50, 1275 (2002).

${ }^{9}$ P. Sindzingre, D. M. Ceperley, and M. L. Klein, Phys. Rev. Lett. 67, 1871 (1991)

${ }^{10}$ K. B. Whaley, Int. Rev. Phys. Chem. 13, 41 (1994).

${ }^{11}$ Y. Kwon and K. B. Whaley, Phys. Rev. Lett. 89, 273401 (2002).

${ }^{12}$ F. Mezzacapo and M. Boninsegni, Phys. Rev. Lett. 97, 045301 (2006).

${ }^{13}$ S. A. Khairallah, M. B. Sevryuk, D. M. Ceperley, and J. P. Toennies, Phys. Rev. Lett. 98, 183401 (2007).

${ }^{14}$ F. Mezzacapo and M. Boninsegni, Phys. Rev. Lett. 100, 145301 (2008).

${ }^{15}$ K. von Haeften, T. Laarmann, H. Wabnitz, and T. Möller, J. Electron Spectrosc. Relat. Phenom. 106, 199 (2000).

${ }^{16}$ S. Grebenev, B. Sartakov, J. P. Toennies, and A. F. Vilesov, Science 289 , $1532(2000)$

${ }^{17}$ E. P. Bernard, R. E. Boltnev, V. V. Khmelenko, V. Kiryukhin, S. I. Kiselev, and D. M. Lee, Phys. Rev. B 69, 104201 (2004).

${ }^{18}$ S. Kuma, H. Goto, M. N. Slipchenko, A. F. Vilesov, A. Khramov, and T. Momose, J. Chem. Phys. 127, 214301 (2007).

${ }^{19}$ G. Tejeda, J. M. Fernández, S. Montero, D. Blume, and J. P. Toennies, Phys. Rev. Lett. 92, 223401 (2004).

${ }^{20}$ J. Soullard, R. Santamaria, and J. Jellinek, J. Chem. Phys. 128, 064316 (2008).

${ }^{21}$ K. Buchheit and W. Henkes, Z. Angew. Phys. 24, 191 (1968).

${ }^{22}$ R. Clampitt and L. Gowland, Nature (London) 223, 815 (1969).

${ }^{23}$ A. van Deursen and J. Reuss, Int. J. Mass Spectrom. Ion Phys. 11, 483 (1973).

${ }^{24}$ A. van Lumig and J. Reuss, Int. J. Mass Spectrom. Ion Phys. 27, 197 (1978)

${ }^{25}$ Y. K. Bae, P. C. Cosby, and D. C. Lorents, Chem. Phys. Lett. 159, 214 (1989).

${ }^{26}$ S. L. Anderson, T. Hirooka, P. W. Tiedemann, B. H. Mahan, and Y. T. Lee, J. Chem. Phys. 73, 4779 (1980).

${ }^{27}$ T. Fiegele, G. Hanel, O. Echt, A. Stamatovic, P. Scheier, and T. D. Märk, J. Phys. B 37, 4167 (2004).

${ }^{28}$ Y. Ekinci, E. L. Knuth, and J. P. Toennies, J. Chem. Phys. 125, 133409 (2006).

${ }^{29}$ A. A. Radzig and B. M. Smirnov, Reference Data on Atoms, Molecules, and Ions (Springer, Heidelberg, 1985).

${ }^{30}$ NIST Chemistry WebBook, http://webbook.nist.gov/.

${ }^{31}$ W. Adeagbo and P. Entel, Phase Transitions 77, 63 (2004).

${ }^{32}$ H. Tachikawa, Phys. Chem. Chem. Phys. 2, 4702 (2000).

${ }^{33}$ O. Kornilov and J. P. Toennies, J. Chem. Phys. 128, 194306 (2008).

${ }^{34}$ S. Raynor and D. R. Herschbach, J. Phys. Chem. 87, 289 (1983).

${ }^{35}$ M. Farizon, H. Chermette, and B. Farizon-Mazuy, J. Chem. Phys. 96, 1325 (1992)

${ }^{36}$ U. Nagashima, K. Morokuma, and H. Tanaka, J. Phys. Chem. 96, 4294 (1992).
${ }^{37}$ B. Diekmann, P. Borrmann, and E. R. Hilf, Surf. Rev. Lett. 3, 253 (1996).

${ }^{38}$ E. W. Ignacio and S. Yamabe, Chem. Phys. Lett. 287, 563 (1998).

${ }^{39}$ M. Barbatti, G. Jalbert, and M. A. C. Nascimento, J. Chem. Phys. 113, $4230(2000)$

${ }^{40}$ H. Chermette and I. V. Ymmud, Phys. Rev. B 63, 165427 (2001).

${ }^{41}$ P. Bokes, I. Stich, and L. Mitas, Int. J. Quantum Chem. 83, 86 (2001).

${ }^{42}$ M. Barbatti, G. Jalbert, and M. A. C. Nascimento, J. Chem. Phys. 114, 7066 (2001)

${ }^{43}$ I. A. Howard, J. A. Alonso, N. H. March, A. Rubio, and C. Van Alsenoy, Phys. Rev. A 68, 065201 (2003).

${ }^{44}$ A. Barbatti and M. A. C. Nascimento, Braz. J. Phys. 33, 792 (2003).

${ }^{45}$ Z. F. Pan and R. F. Borkman, J. Chem. Phys. 101, 7782 (1994).

${ }^{46}$ R. Prosmiti, A. A. Buchachenko, P. Villarreal, and G. Delgado-Barrio, Theor. Chem. Acc. 106, 426 (2001).

${ }^{47}$ M. Kaczorowska, S. Roszak, and J. Leszczynski, J. Phys. Chem. 105, 7938 (2001)

${ }^{48}$ I. Stich, D. Marx, H. Parrinello, and K. Terakura, Phys. Rev. Lett. 78, 3669 (1997).

${ }^{49}$ F. Kirchner, Z. Naturforsch. A 18, 879 (1963).

${ }^{50}$ M. Saporoschenko, J. Chem. Phys. 42, 2760 (1965).

${ }^{51}$ D. Mathur and J. B. Hasted, Nature (London) 280, 573 (1979).

${ }^{52}$ The most intense ion peak in a published mass spectrum (Ref. 28), allegedly due to a "magic" $\mathrm{D}_{10}{ }^{+}$, is clearly not located midway between $\mathrm{D}_{9}{ }^{+}$ and $\mathrm{D}_{11}{ }^{+}$.

${ }^{53}$ N. J. Kirchner and M. T. Bowers, J. Chem. Phys. 86, 1301 (1987).

${ }^{54}$ A. Sanov and W. C. Lineberger, Phys. Chem. Chem. Phys. 6, 2018 (2004).

${ }^{55}$ F. Stienkemeier and K. K. Lehmann, J. Phys. B 39, R127 (2006).

${ }^{56}$ M. Y. Choi, G. E. Douberly, T. M. Falconer, W. K. Lewis, C. M. Lindsay, J. M. Merritt, P. L. Stiles, and R. E. Miller, Int. Rev. Phys. Chem. 25, 15 (2006).

${ }^{57}$ Y. Kurosaki and T. Takayanagi, J. Chem. Phys. 109, 4327 (1998).

${ }^{58}$ S. Denifl, F. Zappa, I. Mähr, J. Lecointre, M. Probst, T. D. Märk, and P. Scheier, Phys. Rev. Lett. 97, 043201 (2006).

${ }^{59}$ S. Feil, K. Gluch, O. Echt, P. Scheier, and T. D. Märk, Int. J. Mass Spectrom. 252, 166 (2006).

${ }^{60}$ F. Zappa, S. Denifl, I. Mähr, J. Lecointre, F. Rondino, O. Echt, T. D. Märk, and P. Scheier, Eur. Phys. J. D 43, 117 (2007).

${ }^{61}$ F. Zappa, S. Denifl, I. Mähr, A. Bacher, O. Echt, T. D. Märk, and P. Scheier, J. Am. Chem. Soc. 130, 5573 (2008).

${ }^{62}$ S. Denifl, M. Stano, A. Stamatovic, P. Scheier, and T. D. Märk, J. Chem. Phys. 124, 054320 (2006).

${ }^{63}{ }^{40} \mathrm{Ar}^{2+}$ becomes visible in Fig. 1 at high hydrogen pressure, indicating an argon impurity in the hydrogen gas. As nearly all other observed ions are singly charged, we label the abscissa of our mass spectra by the mass $m$ (in units of $\mathrm{Da}$ ) rather than the mass-to-charge ratio $\mathrm{m} / \mathrm{q}$ (units of $\mathrm{Th}$ ) (Ref. 64).

${ }^{64}$ R. G. Cooks and A. L. Rockwood, Rapid Commun. Mass Spectrom. 5, 93 (1991)

${ }^{65}$ D. R. Lide, CRC Handbook of Chemistry and Physics (CRC, Boca Raton, 1995).

${ }^{66}$ R. Fröchtenicht, U. Henne, J. P. Toennies, A. Ding, M. Fieber-Erdmann, and T. Drewello, J. Chem. Phys. 104, 2548 (1996).

${ }^{67}$ S. Denifl, F. Zappa, I. Mähr, A. Mauracher, M. Probst, A. Bacher, O. Echt, T. D. Märk, and P. Scheier (submitted)

${ }^{68}$ Kirchner and Bowers (Ref. 53) reported significant collision-induced contributions to MIKE spectra of $\mathrm{H}_{6}{ }^{+}$at a background pressure of $10^{-7} \mathrm{~Pa}$, two orders of magnitude below the pressure in our instrument. However, their ions were prepared differently, by ion-molecule reactions in a drift source. The preparation will affect the excitation energy of the ions and thus the probability of unimolecular dissociation.

${ }^{69}$ D. Schröder and D. Sülzle, J. Chem. Phys. 94, 6933 (1991).

${ }^{70}$ C. Lifshitz, J. Laskin, and T. Peres, Org. Mass Spectrom. 28, 1001 (1993).

${ }^{71}$ J. Fedor, O. Echt, K. Gluch, S. Matt-Leubner, P. Scheier, and T. D. Märk, Chem. Phys. Lett. 437, 183 (2007).

${ }^{72}$ L. R. Wright and R. F. Borkman, J. Chem. Phys. 77, 1938 (1982).

${ }^{73}$ J. A. Montgomery and H. H. Michels, J. Chem. Phys. 87, 771 (1987).

${ }^{74}$ Y. Kurosaki and T. Takayanagi, Chem. Phys. Lett. 293, 59 (1998).

${ }^{75}$ T. H. Dunning, J. Chem. Phys. 90, 1007 (1989).

${ }^{76}$ M. Head-Gordon, J. A. Pople, and M. J. Frisch, Chem. Phys. Lett. 153, 503 (1988).

${ }^{77}$ R. Krishnan and J. A. Pople, Int. J. Quantum Chem. 14, 91 (1978). 
${ }^{78}$ R. Krishnan, M. J. Frisch, and J. A. Pople, J. Chem. Phys. 72, 4244 (1980).

${ }^{79}$ J. Kumagai, H. Inagaki, S. Kariya, T. Ushida, Y. Shimizu, and T. Kumada, J. Chem. Phys. 127, 024505 (2007).

${ }^{80}$ A. Kakizaki, T. Takayanagi, and M. Shiga, Chem. Phys. Lett. 449, 28 (2007).

${ }^{81}$ J. A. Pople, M. Head-Gordon, and K. Raghavachari, J. Chem. Phys. 87, 5968 (1987).

${ }^{82}$ D. E. Woon and T. H. Dunning, Jr., J. Chem. Phys. 98, 1358 (1993).

${ }^{83}$ R. A. Kendall, J. T. H. Dunning, and R. J. Harrison, J. Chem. Phys. 96, 6796 (1992)

${ }^{84}$ We assume that the hyperthermal hydrogen atom would, once separated from the fragment ion, escape from the droplet. This hypothesis may be tested by embedding hydrogen clusters into larger helium droplets.

${ }^{85}$ V. Vorsa, P. J. Campagnola, S. Nandi, M. Larsson, and W. C. Lineberger, J. Chem. Phys. 105, 2298 (1996).

${ }^{86}$ R. Zadoyan, Z. Li, C. C. Martens, and V. A. Apkarian, J. Chem. Phys. 101, 6648 (1994).

${ }^{87}$ N. H. Nahler, M. Fárník, U. Buck, H. Vach, and R. B. Gerber, J. Chem. Phys. 121, 1293 (2004)

${ }^{88}$ H. Shinohara, N. Nishi, and N. Washida, J. Chem. Phys. 84, 5561 (1986).

${ }^{89}$ R. Fröchtenicht, M. Kaloudis, M. Koch, and F. Huisken, J. Chem. Phys. 105, 6128 (1996)

${ }^{90}$ M. Lewerenz, B. Schilling, and J. P. Toennies, J. Chem. Phys. 102, 8191 (1995).

${ }^{91}$ S. Yang, S. M. Brereton, S. Nandhra, A. M. Ellis, B. Shang, L.-F. Yuan, and J. Yang, J. Chem. Phys. 127, 134303 (2007).

${ }^{92}$ W. K. Lewis, C. M. Lindsay, R. J. Bemish, and R. E. Miller, J. Am. Chem. Soc. 127, 7235 (2005).

${ }^{93}$ Y. Ren and V. V. Kresin, J. Chem. Phys. 128, 074303 (2008).

${ }^{94}$ S. Denifl, F. Zappa, I. Mähr, A. Mauracher, M. Probst, T. D. Märk, and P. Scheier, J. Am. Chem. Soc. 130, 5065 (2008).

${ }^{95}$ M. Hartmann, R. E. Miller, J. P. Toennies, and A. Vilesov, Phys. Rev. Lett. 75, 1566 (1995).

${ }^{96}$ C. E. Klots, J. Phys. Chem. 92, 5864 (1988).
${ }^{97}$ U. Näher and K. Hansen, J. Chem. Phys. 101, 5367 (1994).

${ }^{98}$ C. E. Klots, Nature (London) 327, 222 (1987).

${ }^{99}$ M. Farnik and J. Toennies, J. Chem. Phys. 122, 014307 (2005).

${ }^{100}$ K. Gluch, S. Matt-Leubner, L. Michalak, O. Echt, A. Stamatovic, P. Scheier, and T. D. Märk, J. Chem. Phys. 120, 2686 (2004).

${ }^{101}$ W. Paul, S. Schlemmer, B. Lucke, and D. Gerlich, Chem. Phys. 209, 265 (1996).

${ }^{102}$ S. Eden, J. Tabet, K. Samraoui, S. Louc, B. Farizon, M. Farizon, S. Ouaskit, and T. D. Märk, Phys. Rev. A 73, 023201 (2006).

${ }^{103}$ K. Hiraoka and T. Mori, Chem. Phys. Lett. 157, 467 (1989).

${ }^{104}$ M. Okumura, L. I. Yeh, and Y. T. Lee, J. Chem. Phys. 88, 79 (1988).

${ }^{105}$ A. C. Reber, S. N. Khanna, and A. W. Castleman, J. Am. Chem. Soc. 129, 10189 (2007).

${ }^{106}$ M. R. Hoare, Adv. Chem. Phys. 40, 49 (1979).

${ }^{107}$ O. Echt, K. Sattler, and E. Recknagel, Phys. Rev. Lett. 47, 1121 (1981).

${ }^{108}$ I. A. Harris, R. S. Kidwell, and J. A. Northby, Phys. Rev. Lett. 53, 2390 (1984).

${ }^{109}$ T. P. Martin, Phys. Rep. 273, 199 (1996).

${ }^{110}$ S. Prasalovich, K. Hansen, M. Kjellberg, V. N. Popok, and E. E. B. Campbell, J. Chem. Phys. 123, 084317 (2005).

${ }^{111}$ A. Bastida and F. X. Gadea, Chem. Phys. 209, 291 (1996).

${ }^{112}$ B. v. Issendorff, A. Hofmann, and H. Haberland, J. Chem. Phys. 111, 2513 (1999)

${ }^{113}$ T. D. Märk and P. Scheier, J. Chem. Phys. 87, 1456 (1987).

${ }^{114}$ W. Miehle, O. Kandler, T. Leisner, and O. Echt, J. Chem. Phys. 91, 5940 (1989).

${ }^{115}$ O. Kandler, T. Leisner, O. Echt, and E. Recknagel, Z. Phys. D: At., Mol. Clusters 10, 295 (1988).

${ }^{116}$ O. Echt, O. Kandler, T. Leisner, W. Miehle, and E. Recknagel, J. Chem. Soc., Faraday Trans. 86, 2411 (1990).

${ }^{117}$ T. D. Märk and P. Scheier, Chem. Phys. Lett. 137, 245 (1987).

${ }^{118}$ W. Miehle, O. Echt, O. Kandler, T. Leisner, and E. Recknagel, Z. Phys. D: At., Mol. Clusters 12, 273 (1989).

${ }^{119}$ F. Mezzacapo and M. Boninsegni, Phys. Rev. A 75, 033201 (2007). 